\title{
GAMBARAN PELAKSANAAN PERAN KADER TUBERKULOSIS PADA PROGRAM DOTS DI KECAMATAN BANDUNG KULON
}

\author{
${ }^{1}$ Desy Indra Yani, ${ }^{2}$ Risca Ayu Hidayat, ${ }^{3}$ Citra Windani Mambang Sari \\ ${ }^{1,3}$ Departemen Keperawatan Komunitas, Universitas Padjadjaran \\ E-mail: desyindrayani@gmail.com \\ ${ }^{2}$ Mahasiswa Fakultas Keperawatan, Universitas Padjadjaran \\ E-mail: riscaayuhidayat@gmail.com
}

\begin{abstract}
Abstrak
Strategi DOTS direkomendasikan oleh WHO sejak tahun 1995 untuk penanggulangan penyakit TB. Keberhasilan pelaksanaan DOTS di masyarakat perlu melibatkan peran petugas kesehatan, keluarga, dan kader komunitas yang telah mengikuti pelatihan. Keberadaan kader TB di tengah masyarakat ini diharapkan dapat membantu penanggulangan penyakit TB. Tujuan penelitian untuk mengetahui gambaran pelaksanaan peran kader tuberkulosis pada program DOTS di Kecamatan Bandung Kulon. Penelitian ini dilakukan secara deskriptif dengan pendekatan kuantitatif. Terdiri atas satu variabel dengan lima domain. Sampel dalam penelitian adalah 66 kader tuberkulosis yang telah mengikuti pelatihan. Instrumen penelitian ini menggunakan kuesioner melalui teknik wawancara. Kuesioner yang digunakan sudah dilakukan uji validitas isi dilakukan pada tiga peneliti TB dan komunitas. Uji reliabilitas dengan Kuder Richardson formula 21 dengan nilai 0,88 . Nilai uji reliabilitas instrumen 0,8 . Analisis data menggunakan distribusi frekuensi yang dilakukan secara komputerisasi. Hasil penelitian sebagian besar pelaksanaan peran kader tuberkulosis dalam program DOTS dalam kategori baik sebanyak 42 responden $(63,6 \%)$ dan 24 responden $(36,6 \%)$ dalam kategori tidak baik. Domain sebagai pemberi penyuluhan $(63,6 \%)$ dan penjaringan suspek TB $(68,2 \%)$ dalam kategori baik. Akan tetapi, domain peran sebagai koordinator PMO $(63,4 \%)$ dan pembimbing dan pemotivasi PMO $(63,6 \%)$ dalam kategori tidak baik serta domain peran sebagai PMO (50\%) dalam kategori sama baik. Berdasarkan hasil Penelitian diharapkan petugas kesehatan yang menjalani program DOTS dapat mengevaluasi dan memperbaiki aspek yang kurang dalam pelaksanaan peran kader TB.
\end{abstract}

Kata kunci: DOTS, Kader, Tuberkulosis, Peran

\begin{abstract}
DOTS strategy was recommended by WHO since 1995 for TB disease prevention. The successful implementation of DOTS in community need to involve health workers, family, and community health workers (CHWs) who had been trained. The existence of a CHWs of TB in community is expected to assist in controlling TB. Purpose of this research is to describe the implementation of the CHW of tuberculosis roles in DOTS programs in Bandung Kulon. This descriptive study was conducted with a quantitative approach. Consists of one variable with five domains. The sample was 66 CHWs of tuberculosis who had been trained. This study used a questionnaire instrument. The questionnaire used already tested the validity and reliability testing. Value reliability test instruments 0.8 . Analysis of data using frequency distribution is computerized. Results of this study, implementation of the CHWs of tuberculosis roles in DOTS programs were 42 respondents (63.6\%) in good category and 24 respondents (36.6\%) in no good category. The domains as provider outreach and networking suspected tuberculosis in good category. Domain whereas the coordinator's PMO and mentor and motivator PMO in a not good category. The role of the PMO domain in the same category either. Expectation from result of this study that health workers undergoing DOTS program can evaluate and improve aspects lacking in the implementation of the role of the cadre of TB.
\end{abstract}

Keywords: Community health workers, DOTS, Roles, Tuberculosis 


\section{PENDAHULUAN}

Tuberkulosis (TB) merupakan salah satu penyakit yang sampai saat ini menjadi permasalahan global dan penyebab kematian utama bersaing dengan HIV/AIDS pada penyakit menular (WHO, 2018). Angka kematian TB di dunia sebesar 17 per 100.000 orang pada tahun 2016 (WHO, 2018). Setiap tahun terdapat 140 per 100.000 penduduk untuk kasus baru TB (WHO, 2018). Global Report WHO (2018) menyebutkan sekitar 130.000 orang setiap tahunnya meninggal akibat penyakit TB. Lebih dari $95 \%$ kematian akibat TB terjadi di negara berpenghasilan rendah dan menengah. Insidensi $\mathrm{TB}$ di Indonesia sebesar 391 per 100.000 penduduk. Saat ini Indonesia menduduki peringkat ke-2 yang memiliki beban permasalahan TB terbesar setelah India berkontribusi 10,8\% kasus TB di dunia (WHO, 2018).

Kota Bandung sebagai ibu kota dari provinsi Jawa Barat juga tidak luput dari masalah yang ditimbulkan oleh penyakit TB. Menurut profil kesehatan Provinsi Jawa Barat pada tahun 2015, Jawa Barat termasuk dalam sepuluh besar provinsi di Indonesia yang menyumbang angka kejadian TB tertinggi, dengan jumlah kejadian 57.247 kasus. Menurut data dari dinas kesehatan (2018) prevalensi TB di Kota Bandung sebanyak 399 per 100.000 pada tahun 2017 dengan jumlah kasus 9.632 orang. Menurut Dinas Kesehatan Kota Bandung pada tahun 2014, angka penemuan kasus baru TB BTA+ tertinggi berada di Kecamatan Bandung Kulon, yaitu sebanyak 77 kasus.

Penyakit TB adalah penyakit yang dapat disembuhkan jika penderita melakukan pengobatan dan menelan OAT secara teratur selama minimal enam bulan (Ditjen PP\&PL DEPKES RI, 2009). Dalam menangani masalah TB, WHO merekomendasikan pelaksanaan strategi Directly Observed
Treatment Shortcourse (DOTS) pada tahun 1995 dengan lima komponen kunci, yaitu komitmen politik, pemeriksaan dahak mikroskopis, pengobatan jangka pendek yang standar bagi semua kasus TB, jaminan ketersediaan OAT, sistem pencatatan dan pelaporan. Melalui strategi ini diharapkan dapat menurunkan angka kesakitan dan angka kematian akibat penyakit TB (DEPKES RI, 2011).

Keberhasilan pelaksanaan strategi DOTS ini di masyarakat perlu melibatkan peran petugas kesehatan, keluarga, dan kader komunitas yang telah mengikuti pelatihan (WHO, 2013). Dukungan dari luar sektor kesehatan seperti organisasi non pemerintah atau LSM, pemerintah maupun swasta, dan masyarakat sangat diperlukan untuk bersama-sama menanggulangi masalah yang timbul akibat penyakit TB (Community TB Care Aisyiyah, 2009). Kader TB memiliki peran sangat penting dalam memberi pendampingan di masyarakat (Islam, 2013). Pendampingan di masyarakat oleh kader TB bertujuan untuk menurunkan angka pasien yang mangkir atau putus berobat (drop out), meningkatkan angka kesembuhan dan penemuan kasus TB di wilayahnya, serta menghilangkan persepsi negatif masyarakat yang dapat menghambat program pengendalian penyakit TB (Depkes RI, 2009).

Menurut Depkes RI (2009) kader memiliki peran sebagai pemberi penyuluhan terkait penyakit $\mathrm{TB}$, membantu menemukan orang yang dicurigai sakit $\mathrm{TB}$ dan penderita $\mathrm{TB}$, membantu puskesmas dalam membimbing dan memotivasi PMO untuk selalu melakukan pengawasan menelan obat, menjadi koordinator PMO, dan jika pasien tidak memiliki PMO maka kader bisa menjadi PMO. Partisipasi kader TB secara efektif dan maksimal dapat meningkatkan angka rata-rata penyembuhan penyakit TB hingga $80 \%$ 
(Bangladesh Rural Advancement Committee dalam Herce, 2009). Pemberdayaan kader TB terbukti memberikan perubahan dalam meningkatkan angka kesembuhan penyakit TB. Pasien TB di Kenya yang memanfaatkan keberadaan kader TB dapat meningkatkan angka kesembuhan sebesar $83 \%$ dibandingkan pasien TB yang tidak memanfaatkan keberadaan kader ini hanya mencapai 68\% (Ong'ang'O, 2014).

Setiap kader kesehatan agar melaksanakan perannya secara maksimal harus dibekali terlebih dahulu dengan pengetahuan tentang masalah kesehatan yang menjadi perhatiannya dan keterampilan sebagai pembantu petugas kesehatan melalui kegiatan pelatihan kader yang dilakukan oleh dinas kesehatan daerah (Dinkes kota Denpasar, 2013). Dalam pelatihan kader $\mathrm{TB}$, setiap kader dibekali dengan materi tentang konsep dasar penyakit $\mathrm{TB}$, cara menjaring suspek TB, keterampilan berkomunikasi dengan masyarakat, peranan kader kesehatan, serta pencatatan dan pemantauan kasus TB (Dinkes Kota Bandung, 2013). Kader yang telah mengikuti pelatihan dapat meningkatkan penemuan kasus TB sebesar 3,9 \% selama lima tahun (Islam, 2013). Hasil penelitian yang dilakukan oleh Wijaya (2013) kader TB yang memiliki motivasi tinggi memiliki kemungkinan lima belas kali lebih besar untuk aktif dalam melakukan pengendalian penyakit TB daripada kader TB yang memiliki motivasi yang rendah.

Bandung Kulon merupakan daerah tertinggi penemuan kasus TB pada tahun 2013 sebanyak 78 kasus. Kecamatan Bandung Kulon terbagi kedalam tiga wilayah kerja puskesmas dengan angka TB di Puskesmas Cibuntu sebanyak 37 kasus, Puskesmas Cigondewah sebanyak 14 kasus, dan puskesmas Cijerah sebanyak 27 kasus dengan target pencapaian angka penemuan kasus TB
Cibuntu sebanyak 53 kasus, Puskesmas Cigondewah sebanyak 44 kasus, dan puskesmas Cijerah sebanyak 52 kasus. Angka kekambuhan pada tahun 2013 sebanyak 10 orang (Dinkes Kota Bandung, 2013). Untuk mencapai keberhasilan dalam melaksanakan pengobatan tidak hanya peran petugas kesehatan dan keluarga sebagai PMO yang dapat dievaluasi, namun peran kader TB pun dapat dievaluasi karena selain memiliki peran sebagai penjaring atau penemu kasus baru, kader TB ikut berperan dalam hal pemantauan pengobatan dan penyuluhan terkait penyakit TB.

Kader TB di wilayah Kecamatan Bandung Kulon ikut serta membantu petugas kesehatan dalam penanggulangan dan pemantauan pengobatan pasien TB di wilayah kerjanya salah satu cara dengan membantu mendampingi pasien saat pemeriksaan, mengambil obat jika sudah habis, dan memberikan pemahaman bahwa pasien tidak perlu malu mengungkapkan jika terkena penyakit TB agar tidak terjadi drop out atau pengobatan yang gagal. Menurut petugas kesehatan di wilayah kecamatan Bandung Kulon, tidak semua kader TB yang sudah mengikuti pelatihan melaksanakan perannya dengan maksimal salah satunya adalah mencari suspek TB. Kader TB di Kecamatan Bandung Kulon umumnya setiap bulan melaporkan 2-3 orang suspek TB dari total keseluruhan kasus TB. Petugas kesehatan berharap agar setiap kader TB yang sudah mengikuti pelatihan dapat menjalankan setiap perannya secara maksimal agar dapat membantu menanggulangi kasus TB di masyarakat dengan atau tanpa reward yang diberikan. Petugas kesehatan di Bandung Kulon juga menyebutkan bahwa tidak semua kader TB mendapatkan penghargaan jika kader tersebut menemukan suspek TB. Kader TB yang terdaftar dan telah mengikuti 
pelatihan di sebuah LSM yang menangani kasus terkait TB yang memberikan reward berupa insentif kepada kader TB yang menemukan suspek TB.

Perawat komunitas dalam hal ini juga memiliki tanggung jawab dalam upaya meningkatkan kesehatan masyarakat. Perawat komunitas memegang peranan penting dalam pemberdayaan masyarakat dan pemantauan dengan melakukan kerja sama lintas sektor (Anderson, 2007), salah satunya kerja sama dengan kader TB dengan memberikan pendidikan kesehatan dan pembinaan kepada kader TB dalam hal penanggulangan penyakit TB, model peran, dan fasilitator masyarakat termasuk di dalamnya adalah kader TB. Setiap kelurahan memiliki minimal dua kader kesehatan TB. Perawat puskesmas bekerjasama dengan kader kesehatan TB dalam deteksi kasus, mengingatkan pasien TB untuk kontrol ke puskesmas dan pemberikan pendidikan kesehatan di masyarakat.

Berdasarkan fenomena tersebut maka penulis tertarik untuk meneliti dan mendeskripsikannya dalam bentuk penelitian kuantitatif dengan judul "Gambaran Pelaksanaan Peran Kader Tuberkulosis pada Program DOTS di Kecamatan Bandung Kulon”.

\section{METODE PENELITIAN}

Metode yang digunakan dalam penelitian ini adalah deskriptif dengan pendekatan kuantitatif. Penelitian ini bertujuan untuk mengetahui gambaran pelaksanaan peran kader tuberkulosis pada program DOTS di Kecamatan Bandung Kulon. Populasi dalam penelitian ini adalah kader TB yang sudah mengikuti pelatihan tuberkulosis dan berdomisili di wilayah kecamatan Bandung Kulon sebanyak 82 orang. Angka keberhasilan pengobatan pada tahun 2015 adalah $79 \%$ dengan kasus meninggal 2\%, kasus gagal $1 \%$ dan default $10 \%$, dan kasus pindah 7\% Pengambilan sampel dalam penelitian ini dilakukan dengan teknik "total sampling", yaitu keseluruhan populasi sebanyak 82 orang kader tuberkulosis. Namun, tiga belas orang menolak menjadi responden dengan alasan sibuk dan tiga orang sedang berada di luar kota. Total kader tuberkulosis yang menjadi sampel sebanyak 66 orang kader tuberkulosis.

Kuesioner yang digunakan dikembangkan oleh peneliti berdasarkan konsep dari WHO (2013) dan Depkes (2009) yang terdiri dari 25 pertanyaan menggunakan skala Guttman dengan pilihan jawaban ya dan tidak. Instrumen ini menggunakan teknik wawancara dan diisi oleh peneliti dengan cara memberikan check-list pada kolom ya dan tidak sesuai jawaban yang diberikan oleh responden. Instrumen ini telah dilakukan uji validitas dan uji reliabilitas $(0,8)$. Teknik analisis dilakukan secara deskriptif pada variabel yang berlevel nominal dan ordinal ditampilkan dalam bentuk distribusi frekuensi dan persentase.

\section{HASIL PENELITIAN}

Tabel 1 menjelaskan distribusi frekuensi responden berdasarkan karakteristik yang dimiliki responden, dari hasil tersebut diperoleh bahwa sebagian besar responden, yaitu sebanyak 56 responden $(84,8 \%)$ berusia 41-60 tahun, sebanyak 66 responden (100\%) berjenis kelamin perempuan, berada di kelurahan Cigondewah sebanyak 35 responden $(53 \%)$, sebanyak 44 responden $(66,7 \%)$ lulusan SMA sedrajat, sebanyak 54 responden $(81,8 \%)$ bekerja sebagai ibu rumah tangga, sebanyak 34 responden $(51,5 \%)$ berpenghasilan dibawah Rp. 2.000.000, sebanyak 54 responden $(81,8 \%)$ bersuku bangsa sunda, sebanyak 66 responden (100\%) sudah menikah, sebanyak 64 responden (97\%) sudah menjadi kader TB selama 
kurang dari lima tahun, sebanyak 66 responden $(100 \%)$ sudah mengikuti pelatihan, sebanyak 50 responden $(75,8 \%)$ belum pernah mendapatkan reward selama menjadi pasien
TB, sebanyak 33 responden $(80,3 \%)$ pernah merawat pasien TB, dan sebanyak 66 responden $(100 \%)$ menjabat sebagai kader selain kader TB.

Tabel 1.

Distribusi Frekuensi Karakteristik Responden $(\mathrm{n}=66)$

\begin{tabular}{|c|c|c|}
\hline Karakteristik & Frekuensi (f) & Persentase (\%) \\
\hline \multicolumn{3}{|l|}{ Usia (median: 45.5 dan IQR: 7) } \\
\hline $18-40$ & 10 & 15.2 \\
\hline $41-60$ & 56 & 84.8 \\
\hline \multicolumn{3}{|l|}{ Wilayah Kerja } \\
\hline Cibuntu & 20 & 30.3 \\
\hline Cijerah & 11 & 16.7 \\
\hline Cigondewah & 35 & 53 \\
\hline \multicolumn{3}{|l|}{ Jenis Kelamin } \\
\hline Perempuan & 66 & 100 \\
\hline \multicolumn{3}{|l|}{ Pendidikan Terakhir } \\
\hline SD & 5 & 7.6 \\
\hline SMP & 14 & 21.2 \\
\hline SMA/SMK & 44 & 66.7 \\
\hline Universitas & 3 & 4.5 \\
\hline \multicolumn{3}{|l|}{ Pekerjaan } \\
\hline IRT & 54 & 81.8 \\
\hline PNS & 2 & 3 \\
\hline Pegawai Swasta Wiraswasta & 5 & 7.6 \\
\hline Wiraswasta & 5 & 7.6 \\
\hline \multicolumn{3}{|l|}{ Penghasilan } \\
\hline <Rp. 2.000 .000 & 34 & 51.5 \\
\hline$\geq$ Rp. 2.000 .000 & 32 & 48.5 \\
\hline \multicolumn{3}{|l|}{ Suku Bangsa } \\
\hline Batak & 3 & 4.5 \\
\hline Jawa & 9 & 13.6 \\
\hline Sunda & 54 & 81.8 \\
\hline \multicolumn{3}{|l|}{ Status Pernikahan } \\
\hline Menikah & 66 & 100 \\
\hline \multicolumn{3}{|l|}{ Lama Menjadi Kader TB } \\
\hline$<5$ tahun & 64 & 97 \\
\hline$>5$ tahun & 2 & 3 \\
\hline \multicolumn{3}{|l|}{ Pernah Pelatihan Kader TB } \\
\hline Ya & 66 & 100 \\
\hline Aisyiyah & 12 & 18.2 \\
\hline Puskesmas & 39 & 59.1 \\
\hline Cibadak & 15 & 22.7 \\
\hline \multicolumn{3}{|c|}{$\begin{array}{l}\text { Pernah Mendapatkan Reward selama } \\
\text { menjadi kader TB }\end{array}$} \\
\hline Ya & 16 & 24.2 \\
\hline Tidak & 50 & 75.8 \\
\hline \multicolumn{3}{|l|}{ Pernah Merawat pasien TB } \\
\hline Ya & 53 & 80.3 \\
\hline Tidak & 13 & 19.7 \\
\hline \multicolumn{3}{|l|}{ Menjabat sebagai kader lain } \\
\hline Ya & 66 & 100 \\
\hline
\end{tabular}


Tabel 2.

Distribusi Frekuensi dan Persentase

Pelaksanaan Peran Kader Tuberkulosis

pada Program DOTS di Kecamatan

Bandung Kulon $(n=66)$

\begin{tabular}{|l|c|c|c|c|}
\hline \multicolumn{1}{c}{ Variael } & \multicolumn{2}{c}{ Baik } & \multicolumn{2}{c}{ Tidak Baik } \\
f
\end{tabular}

Tabel 2 di atas menerangkan pelaksanaan peran kader tuberkulosis pada program DOTS. Berdasarkan tabel diketahui dari 66 responden, sebanyak 42 responden $(63,6 \%)$ dalam melaksanakan perannya sebagai kader tuberkulosis berada dalam kategori baik dan sebanyak 24 responden $(36,6 \%)$ dalam kategori tidak baik. Hal ini, mengindikasikan bahwa gambaran pelaksanaan peran kader TB di Kecamatan Bandung Kulon dalam kategori baik. Sebanyak 45 responden $(68,2 \%)$ dalam perannya sebagai pemberi penyuluhan berada dalam kategori baik dan sebanyak 21 responden $(31,8 \%)$ dalam kategori tidak baik. Sebanyak 43 responden $(65,2 \%)$ dalam perannya sebagai penjaring suspek TB berada dalam kategori baik dan sebanyak 23 responden $(34,8 \%)$ dalam kategori tidak baik. Sebanyak 24 responden $(36,4 \%)$ dalam perannya sebagai pembimbing dan pemotivasi PMO berada dalam kategori baik dan sebanyak 42 responden $(63,6 \%)$ dalam kategori tidak baik. Sebanyak 24 responden $(36,4 \%)$ dalam perannya sebagai koordinator PMO berada dalam kategori baik dan sebanyak 42 responden $(63,6 \%)$ dalam kategori tidak baik. Sebanyak 33 responden (50\%) dalam perannya sebagai PMO berada dalam kategori baik dan sebanyak 33 responden $(50 \%)$ dalam kategori tidak baik.

\section{PEMBAHASAN}

Dari hasil penelitian secara keseluruhan pelaksanaan peran kader TB dapat dilihat bahwa sebagian besar dari responden termasuk dalam kategori baik $(63,6 \%)$, hal ini akan berdampak positif untuk pemberdayaan masyarakat dan penanggulangan penyakit TB yang berbasis komunitas.

Banyak faktor yang dapat mempengaruhi dalam pelaksanaan peran kader ini seperti usia, motivasi, dan lain-lain. Berdasarkan karakteristik responden penelitian menunjukan kesesuaian yang baik dengan teori maupun hasil penelitian sebelumnya.

Pelaksanaan peran kader TB ini, kader TB memerlukan pengetahuan yang baik dengan mengikuti pelatihan. Seluruh kader TB menyatakan pernah mengikuti pelatihan terkait penyakit TB. Adapun topik yang dijelaskan adalah konsep penyakit TB, cara menjaring suspek TB, PMO dan keterampilan komunikasi. Hasil wawancara dengan kader TB yang telah mengikuti pelatihan menyatakan bahwa dengan mengikuti pelatihan mereka memperoleh manfaat dan pengetahuan terkait penyakit TB. Lindner (2002) menyatakan bahwa kinerja yang efektif membutuhkan pengetahuan, dalam hal ini pengetahuan tersebut dapat diperoleh dengan mengikuti pelatihan-pelatihan. Kader yang telah mengikuti pelatihan memberikan pengaruh dalam melaksanakan perannya sebagai kader (Simanjutak, 2012).

Dalam penelitian ini kader TB paling banyak berada di usia dewasa madya. Semakin bertambah usia seseorang, maka semakin bertambah dewasa dan semakin banyak menyerap pengetahuan. Kader yang memiliki pengetahuan tinggi memiliki kemungkinan untuk melaksanakan perannya delapan belas kali daripada kader yang memiliki pengetahuan rendah (Wijaya, 2013). 
Penghargaan yang didapat oleh kader juga dapat menjadi kontribusi dalam melaksanakan perannya. Penghargaan yang dinginkan umumnya pengakuan atas prestasi, paujian, dan lain-lain. Insentif yang merupakan salah satu bagian dari penghargaan tidak begitu diharapkan oleh kader TB. Hal ini sesuai dengan hasil wawancara dengan kader TB bahwa mereka tidak mengharapkan imbalan atau insentif, karena mereka melakukan pekerjaan sebagai kader didorong atas keinginanan diri sendiri dengan hati yang tulus untuk membantu masyarakat dan bersifat sukarela. Namun, ada beberapa kader yang mendapatkan insentif. Hasil penelitian yang dilakukan oleh Simanjutak (2012) menyebutkan bahwa semakin tinggi insentif yang diterima oleh kader memberikan pengaruh dalam meningkatkan kinerja kader.

Penelitian ini terdiri atas satu variabel yang memiliki lima domain variabel yang diteliti adalah pelaksanaan peran kader TB sebagai pemberi penyuluhan terkait penyakit TB, pelaksanaan peran kader TB sebagai penjaring suspek $\mathrm{TB}$, pelaksanaan peran kader TB Bandung Kulon sebagai berikut: sebagai pembimbing dan pemotivasi PMO, pelaksanaan peran kader TB sebagai koordinator PMO, dan pelaksanaan peran kader TB sebagai PMO. Secara rinci hasil penelitian gambaran pelaksanaan peran kader TB pada program DOTS di Kecamatan Bandung Kulon adalah:

Pada tabel 1.2 di atas dapat diperoleh gambaran pelaksanaan peran kader sebagai pemberi penyuluhan tentang penyakit TB dengan baik yaitu sebanyak 68,2\%, namun, masih ada yang harus ditingkatkan lagi karena sebanyak $31,8 \%$ yang melaksanakan tugas sebagai pemberi penyuluhan tidak baik. Sebagian besar responden yang melakukan penyuluhan tidak baik berpendapat bahwa mereka tidak melakukan penyuluhan karena mereka segan untuk berbicara didepan forum sehinggan lebih memilih untuk melakukan sharing, lima belas orang responden mengatakan sudah ada kader TB yang sering menjadi pemateri dan melakukan penyuluhan, dan tiga orang responden tidak menjelaskan alasannya. Namun, sebagian responden mengatakan penyuluhan penting dilakukan agar masyarakat mengetahui informasi mengenai penyakit TB.

Penyuluhan adalah kegiatan atau usaha untuk menyampaikan pesan kesehatan kepada masyarakat, kelompok, dan individu (Notoadmojo, 2007). Masyarakat yang telah diberikan penyuluhan memiliki pengetahuan yang lebih mengenai penyakit yang disampaikan saat penyuluhan (Sungkar, 2010). Penelitian Suariyani mengatatakan bahwa penyuluhan yang dilakukan dengan menarik dan menggunakan media dapat memudahkan sasaran untuk memahami isi penyuluhan tersebut. Ini dapat terlihat dari antusias dan peningkatan pengetahuan sasaran. Khynn (2004) menyatakan bahwa masyarakat yang sering terpapar berbagai media kesehatan yang digunakan seperti poster, pamflet, televisi, jurnal, dan surat kabar memiliki tingkat pengetahuan yang lebih baik dibandingkan masyarkat yang tidak terpapar media.

Pada tabel 1.2 di atas dapat diperoleh gambaran pelaksanaan peran kader sebagai penjaring suspek TB dengan baik yaitu sebanyak $65,2 \%$, namun, masih ada yang harus ditingkatkan lagi karena sebanyak $34,8 \%$ yang melaksanakan tugas sebagai pemberi penjaring suspek TB kedalam kategori tidak baik.

Kader TB yang melakukan penjaringan suspek TB mempunyai peluang 8,92 kali lebih besar untuk menemukan penderita TB paru dibandingkan dengan kader TB yang tidak melakukan penjaringan suspek TB. 
Kegiatan penjaringan suspek TB sangat berpengaruh terhadap penemuan penderita TB dan penanggulangan penyakit TB (Awusi, 2009). Di Kecamatan Bandung Kulon pada tahun 2013 menjadi kecamatan yang memiliki angka kejadian TB tertinggi di Kota Bandung sebanyak 78 kasus (Dinkes Kota Bandung, 2013).

Pada tabel 1.2 di atas dapat diperoleh gambaran pelaksanaan peran kader sebagai pembimbing dan pemotivasi PMO dengan baik, yaitu sebanyak $34,6 \%$, masih perlu ditingkatkan lagi karena sebanyak 63,6\% yang melaksanakan peran sebagai pemberi pembimbing dan pemotivasi PMO dalam kategori tidak baik. Responden yang tidak melaksanakan perannya berpendapat bahwa PMO yang dipilih untuk mengawasi pasien TB merupakan PMO sudah mengikuti pelatihan PMO dan merupakan anggota keluarga penderita sehingga memiliki kesadaran dalam melaksanakan tugasnya sebagai PMO, dan enam orang responden tidak menjelaskan alasannya.

Menurut Sukmah (2013), mengatakan bahwa sebagian besar PMO tidak mendapatkan penjelasan yang cukup mengenai tugas sebagai PMO. Petugas kesehatan hanya menanyakan nama orang terdekat pasien yang dapat mengambil obatnya dan memberikan dorongan kepada penderita untuk berobat karena kekhawatiran penyakit yang diderita oleh pasien menjadi bertambah parah. Dalam hal ini, kader tuberkulosis yang sudah mengikuti pelatihan bisa membantu petugas kesehatan dalam membimbing dan memotivasi PMO untuk bersama-sama memberikan informasi dan dukungan moral kepada PMO mengenai penyakit TB.

Pada tabel 1.2 di atas dapat diperoleh gambaran pelaksanaan peran kader sebagai koordinator PMO dengan baik yaitu sebanyak $36,4 \%$, namun, masih ada yang harus ditingkatkan lagi karena sebanyak 63,6\% yang melaksanakan tugas sebagai koordinator PMO termasuk dalam kategori yang tidak baik. Kader tuberkulosis yang tidak melakukan peran ini mengatakan bahwa mereka segan bila harus terus mengawasi dan mengevalusi temannya sendiri. 87\% kader tuberkulosis yang tidak melaksanakan peran ini meyakini bahwa PMO sudah memiliki kesadaran tanpa harus diawasi dan dievaluasi.

Menurut Nepal (2012) PMO yang lupa mengisi kartu pengobatan pasien dapat menyebabkan kesalahan dalam pelaporan mengenai pengobatan dan menjadi salah satu alasan penghentian pengobatan karena merasa kondisi pasien sudah membaik dan efek samping dari obat-obatan yang berkepanjangan. Untuk itu, seorang kader harus membantu petugas kesehatan dalam hal mengawasi perkembangan pengobatan dan pengisian kartu kontrol pasien.

Pada tabel 1.2 diatas dapat diperoleh gambaran pelaksanaan peran kader sebagai PMO sama baiknya. Pengobatan tuberkulosis memerlukan PMO untuk menjamin keteraturan pengobatan selama pengobatan. Bila, penderita TB berhenti ditengah pengobatan maka pengobatan harus diulangi dari awal untuk itu diperlukan PMO yang dipercaya oleh penderita sehingga kepatuhan obat sesuai (Depkes, 2009).

Keterlibatan PMO berpengaruh besar pada ketaatan pasien melakukan pengobatan. (Heryanto, 2004). Tidak adanya PMO dapat menjadi salah satu faktor membuat pasien TB menghentikan pengobatannya. Retnowati (2002) menyatakan bahwa kegagalan pengobatan disebabkan putusnya pengobatan adalah akibat kurangnya pengawasan dan kerja sama penderita. Tidak adanya PMO bagi pasien disebabkan pasien tidak mengajak keluarganya saat pasien melakukan pemeriksaan dan pengambilan obat, hal 
tersebut karena penunjukan PMO yang dilakukan petugas kesehatan hanya kepada keluarga pasien yang ikut dengan pasien (Nugroho, 2011).

\section{SIMPULAN DAN SARAN}

Berdasarkan hasil penelitian tentang Gambaran Pelaksanaan Peran Kader Tuberkulosis pada Program DOTS di Kecamatan Bandung Kulon dapat disimpulkan bahwa secara keseluruhan didapatkan hasil pelaksanaan peran kader tuberkulosis pada program DOTS di Kecamatan Bandung Kulon memperlihatkan dalam kategori baik $(63,6 \%)$. Domain peran kader TB sebagai pemberi penyuluhan dan penjaring suspek TB dalam kategori baik. Peran kader TB pembimbing dan pemotivasi PMO serta koordinator PMO dalam kategori tidak baik. Sedangkan, peran kader TB sebagai PMO dalam kategori sama baik.

\section{UCAPAN TERIMA KASIH}

Ucapan terima kasih diberikan kepada semua responden yang terlibat dalam penelitian ini.

\section{REFERENSI}

Anderson, E., McFarlane, J. 2007. Buku Ajar Keperawatan Komunitas Teori dan Praktik Edisi 3. Jakarta: EGC.

Awusi, R.Y., Saleh, Y.D., Hadiwijoyo, D. 2009. Faktor-faktor yang mempengaruhi penemuan penderita TB paru di Kota Palu Provinsi Sulawesi Tengah. Berita Kedokteran Masyarakat 25(2): 59-68.

Community TB CARE. 2009. Modul I tuberkulosis dan penanggulangannya. Tidak dipublikasikan. . 2009. Modul II peran komunitas dalam penanggulangan tuberculosis di Indonesia. Tidak dipublikasikan.

Departemen Kesehatan Republik Indonesia. 2009. Buku saku kader program penanggulangan TB.Jakarta: Ditjen PP\&PL.

Dinas Kesehatan Kota Bandung. 2011 . Data penyakit tuberkulosis di Kota Bandung. $\quad$ Bandung: Tidak dipublikasikan.

Dinkes Kota Denpasar. 2013. Pelatihan kader tuberkulosis melalui desa Pakraman.http://dinkes.denpasarkota. go.id/index.php/bacaberita/6151/Pelatihan-KaderTuberculosis-awalTBakhir-MelaluiDesa-Pakraman. Diakses Pada Januari 2014.

Herce, M., et al. 2009. A Role for community health promoters In tuberculosis control in the state of Chiapas, Mexico. Springer Sciences+Busines Media.

Herryanto, Komalig, F., Sukana, B., Musadad, B. A. 2004. Peranan Pengawas Menelan Obat Pada Kejadian Putus Berobat Penderita TB Paru di DKI Jakarta Tahun 2002. Media Litbang Kesehatan Volume XIV Nomor 2 Tahun 2004.

Islam, S. 2013. Training of community healthcare providers and $T B$ case detection. Bangladesh: International Health; 5(3):223-7.

Khynn TW, Sian ZN, Aye M. 2004. Community-based assessment of dengue-related knowledge among caregivers. Dengue Bulletin 2004; 28:189-95

Kementerian Kesehatan Republik Indonesia.2011. Strategi nasional pengendalian TB di Indonesia 20102014. Jakarta: tidak dipublikasikan.

Lindner, J.R. Dooley, K.E., 2002. Agricultural Education Competencies and Progress towards a Doctoral Degree. Journal of Agricultural Education. Vol. 43, No. 1. pp. 57-68.

Nepal AK, Shiyalap K,Sermsri S, Keiwkarnka B. 2012. Compliance with DOTS among tuberculosis patients under community based DOTS strategy in Palpa District, Nepal. Int J Infect Microbiol. 1(1):14-19. 
Notoatmodjo, Soekidjo.2007. Promosi Kesehatan Dan Ilmu Perilaku. Jakarta: Rineka Cipta.

Nugroho, R. A. Studi Kualitatif Faktor Yang Melatarbelakangi Drop Out Pengobatan Tuberkulosis Paru. KEMAS 7 (1) (2011) 83-90

Ong'ang'o, J.R et al. 2014. The effect on tuberculosis treatment adherence from utilising community health workers: A comparison of selected rural and urban settings in Kenya. PLoS ONE 9(2): e88937. doi:10.1371/journal.

Simanjutak, M. 2012. Karakteristik sosial demografi dan faktor pendorong peningkatan kinerja pposyandu. Jurnal Wira Ekonomi Mikroskil. Volume 2, Nomor 01, April 2012.

Sukmah, Mahyudin, Suarnianti. 2013. Faktorfaktor yang berhubungan dengan kepatuhan berobat pada pasien TB paru di RSUD Makassar. Volume 2 Nomor 5 Tahun 2013, ISSN : 23021721.

Sungkar, S., Winita, R., Kurniawan, A. 2010. Pengaruh penyuluhan terhadap tingkat pengetahuan masyarakat dan kepadatan Aedes aegypti di kecamatan Bayah, Provinsi Banten. MAKARA, KESEHATAN, VOL. 14, NO. 2, DESEMBER 2010: 81-85

WHO : DOTS. 2012. Pursue high-quality DOTS expansion and enhancement http://www.who.int/tb/dots/en/. Diakses Januari 2014.

WHO TB Data. 2018. Global tuberculosis report 2017 http://www.who.int/tb/ country/en/. Diakses Pada Juni 2018.

WHO. 2014. Track 1: Community empowerment 7th Global Conference on Health Promotion: Track themes.http://www.who.int/healthpro motion/conferences/7gchp/track1/en/\#

Wijaya, I. M. 2013. Pengetahuan, sikap, dan motivasi terhadap keaktifan kader dalam pengendalian tuberkulosis. Kemas 8(2) (2013): 137-144. http://journal.unnes.ac.id/nju/index.ph p/kemas. Diakses Pada Januari 2014. 